\title{
Comparative Studies on Trade and Value-Added Trade along the "Belt and Road": A Network Analysis
}

\author{
Guangjun Sui, ${ }^{1}$ Jialing Zou $\mathbb{D}^{1},{ }^{1}$ Shuang $W u\left(\mathbb{D},{ }^{2}\right.$ and Danling Tang ${ }^{3,4}$ \\ ${ }^{1}$ Guangdong Institute for International Strategies, Guangdong University of Foreign Studies, Guangzhou 510420, China \\ ${ }^{2}$ Division of Humanities and Social Sciences, \\ Beijing Normal University-Hong Kong Baptist University United International College, Zhuhai 519087, China \\ ${ }^{3}$ Southern Marine Science and Engineering Guangdong Laboratory (Guangzhou), Guangzhou, China \\ ${ }^{4}$ Guangdong Key Laboratory of Ocean Remote Sensing, State Key Laboratory of Tropical Oceanography, \\ South China Sea Institute of Oceanology, Chinese Academy of Sciences, Guangzhou 511458, China \\ Correspondence should be addressed to Shuang Wu; sharon9081@life.hkbu.edu.hk
}

Received 27 May 2021; Revised 21 July 2021; Accepted 7 August 2021; Published 14 August 2021

Academic Editor: Fabio Saracco

Copyright $(2021$ Guangjun Sui et al. This is an open access article distributed under the Creative Commons Attribution License, which permits unrestricted use, distribution, and reproduction in any medium, provided the original work is properly cited.

\begin{abstract}
With the deepening of regional industrial transfer, traditional trade data cannot fully explain the real level of trade in a region. This paper aims to reveal the changing pattern of real trade along the "Belt and Road" by establishing a value-added trade (VAT) network of the "Belt and Road" countries and comparing it with the trade network. Applying a network method, we analyze and compare the structures, characteristics, evolutions, and underlying dynamisms of both networks. With a thorough interpretation and visualization of the network density, network centrality, trade communities, and influencing factors of both networks in the three time sections of 2005, 2010, and 2015, we come to the following findings: (1) the connectivity of both networks has been greatly enhanced, reflecting a more integrated regional economy. (2) The center-external structure of both networks has been further strengthened and the polarization of the VAT network is more obvious than that of the trade network. (3) The organizations of trade communities and VAT communities are largely different. Specifically, China rapidly increased its core position in the VAT network and incorporated more and more countries into its VAT community. (4) The underlying factors have similar impacts on both networks. While the growth of regional economic size and free trade agreements will enhance both trade and VAT, the economic gaps and population differences among the "Belt and Road" countries will prohibit regional economic ties. Based on these findings, we propose suggestions on further regional economic cooperation by taking advantage of China's core position to promote regional VAT, construct broad trade channels, and enhance trade governance.
\end{abstract}

\section{Introduction}

The "Belt and Road initiative" (BRI) is China's greatest international economic envisagement, aiming at stimulating economic development in a vast region covering countries in Asia, Europe, and Africa with the theme of infrastructure development, policy dialogue, unimpeded trade, financial support, and people-to-people exchange. Since it was proposed in 2013, trade ties among the BRI countries have become increasingly closer, facilitating a tighter intraregional trade network. This also deepened the transfer of industries and the division of labor within the BRI region. With the deepening of regional industrial transfer and production cooperation, traditional trade data cannot adequately account for the true level of trade because the export products of one country may contain the import of raw and processed materials from another country. Compared with the trade data, VAT data can counteract on this effect and better reflect the true level of trade [1]. Our paper aims to reveal the changing pattern of the true level of trade of the BRI region by comparing the VAT network with the trade network. Through analyzing the structures, characteristics, evolutions, and underlying dynamisms of both trade network and VAT network of the BRI region, we try to fully interpret the development and change of trade among the BRI countries and propose pertinent suggestions for 
future regional trade cooperation and production connection.

Since the global and regional trade networks maintain distinctive hallmarks of networks, scholars have taken network methods to analyze the trade networks and explore the intricate relations of trade among countries and regions [2]. For example, Garlaschelli and Loffredo [3] and De Benedictis and Tajoli [4] took network analysis to delineate the global trade network structure. De Benedictis and Tajoli [4] pointed out that the evolution of trade network has great impact on trade relations and trade policies. Using network methods, scholars also analyzed the topology, community structure, and evolution of world trade web [5-7]. Taking a further step, Jiang et al. [8] analyzed the evolution of global trade communities and proposed directions for China's geopolitical strategies. Network methods also played an important role in analyzing product trade networks, especially the global trade networks of energy and mineral products $[9,10]$, agricultural products [11], waste products $[12,13]$, and other important products $[14,15]$. These studies are not only of great value in comprehending the characteristics of product trade networks but also help to understand the organizations and patterns of global production networks and global geopolitical relations.

The proposition of BRI accelerates research on trade networks in the BRI region. Taking the overall BRI trade network as the research object, scholars analyze the evolutionary characteristics of the network structure, changes in trade communities, and carry out an in-depth description of the BRI trade network in recent years $[16,17]$. On this basis, Chong et al. [18] discussed the forming factors and influence of proximity, culture, and institutions on the structure of the BRI trade network. Chen et al. [19] further analyzed the cultural trade network of the BRI countries and its evolution. Incorporating the BRI trade network into the global trade network, Song et al. [20, 21] compared the topological structure of the BRI trade network with that of the global trade network and sorted out the relationship between the trade communities in the BRI trade network and those in the global trade network. Other scholars paid attention to the structures and influencing factors of the trade network of industries and subdivided products among the BRI countries, including the high-end manufacturing [22], agriculture [23], and natural gas [24].

Due to the deepening of international industrial division of labor, the traditional international trade data cannot fully reflect the true level of trade. In order to measure the evolution of the network structure of the real trade between regions, research on trade networks based on value added has recently begun to emerge. Ferrarini [25] first measured and visualized the global vertical VAT network and found that the central position of China's automobile and electronics industry was rising. Cerina et al. [26] and Zhu et al. [27] used the network method to analyze the VAT in the global trade network and described the specific form of the global value chain. By calculating the foreign value-added part of each country's export trade, Amador and Cabral [28] built a global nonweighted VAT network and depicted its structural evolutionary characteristics. They found that large trading countries play a key role in the VAT network. In addition, based on the network analysis method, Sun et al. [29] depicted the topological structure of the global manufacturing VAT network and further discussed the factors affecting its structural evolution. Focusing on the manufacturing VAT network of the BRI countries, scholars found a rapid growth trend after 2003, largely influenced by the regional trade agreement relationship and the increase in economic aggregates [30].

Taken together, there is a growing body of literature on trade among the BRI countries based on network analysis. These studies have portrayed the trade network structure of the BRI region as well as its evolutionary characteristics and influencing factors. Compared with the traditional trade, VAT can better reflect the true level of trade [31]. Research based on VAT network analysis has also shown a rising trend. However, few studies have considered the VAT of the BRI region, let alone to describe its evolutionary characteristics.

To fill in this gap, we try to establish the BRI VAT network and analyze its structure, characteristics, evolution, and underlying dynamism with a comparison of the BRI trade network. In the following parts, we first introduce the method and data we employed for calculating the VAT among the BRI countries and establishing the BRI VAT network as weighted networks. We then compare the BRI trade network with the BRI VAT network by the three descriptors of network density, network centrality, and trade communities, combined with a further exploration of their evolutionary trends. In the next part, we build up a model analyzing the factors that influence the two networks to understand their underlying dynamisms and differences. Based on the above analysis, we finally come to the conclusion and propose pertinent policy suggestions for strengthening the trade links among the BRI countries. By analyzing the evolution of trade and VAT network of the BRI countries, this paper will help understand the significance of the BRI, especially from the perspective how BRI strengthened economic linkages.

\section{Method and Data}

2.1. Research Area. The BRI insists an ethos of inclusiveness, which does not restrict to a limited geographical space [32]. Yet, for the convenience of research, scholars usually have their own definitions of the spatial scope of the BRI $[16,33]$. Given the availability of international input-output table data and based on previous related research, the BRI countries in this article refer to China and the following 63 countries, as shown in Table 1 and Figure 1.

2.2. Data Source. For the network construction, we use two main sorts of data, the export trade data among the BRI countries and the intercountry input-output tables of the BRI region. The export trade data between countries in each year comes from the International Trade Center (https:// www.trademap.org/). In terms of the intercountry 
TABLE 1: The BRI countries indicated in this paper.

\begin{tabular}{|c|c|}
\hline Subregion & Country \\
\hline Central Asia & Kazakhstan, Kyrgyzstan, Tajikistan, Uzbekistan, Turkmenistan \\
\hline $\begin{array}{l}\text { Mongolia and } \\
\text { Russia }\end{array}$ & Mongolia, Russia \\
\hline Southeast Asia & Vietnam, Laos, Cambodia, Thailand, Malaysia, Singapore, Indonesia, Brunei, Philippines, Myanmar \\
\hline South Asia & India, Pakistan, Bangladesh, Afghanistan, Nepal, Bhutan, Sri Lanka, Maldives \\
\hline Central and & Poland, Czech Republic, Slovakia, Hungary, Slovenia, Croatia, Romania, Bulgaria, Serbia, Montenegro, Kingdom of \\
\hline Eastern Europe & Macedonia, Bosnia and Herzegovina, Albania, Estonia, Lithuania, Latvia, Ukraine, Belarus, Moldova \\
\hline $\begin{array}{l}\text { West Asia and } \\
\text { Middle East }\end{array}$ & $\begin{array}{c}\text { Turkey, Iran, Syria, Iraq, UAE, Saudi Arabia, Qatar, Bahrain, Kuwait, Lebanon, Oman, Yemen, Jordan, Israel, } \\
\text { Armenia, Georgia, Azerbaijan, Egypt }\end{array}$ \\
\hline
\end{tabular}

Note. The BRI region usually contains 66 countries. Because the dataset we referred to, the Eora26 intercountry input-output table, does not include East Timor and Palestine. We excluded East Timor and Palestine from the 66 countries and got the research area with 64 countries.
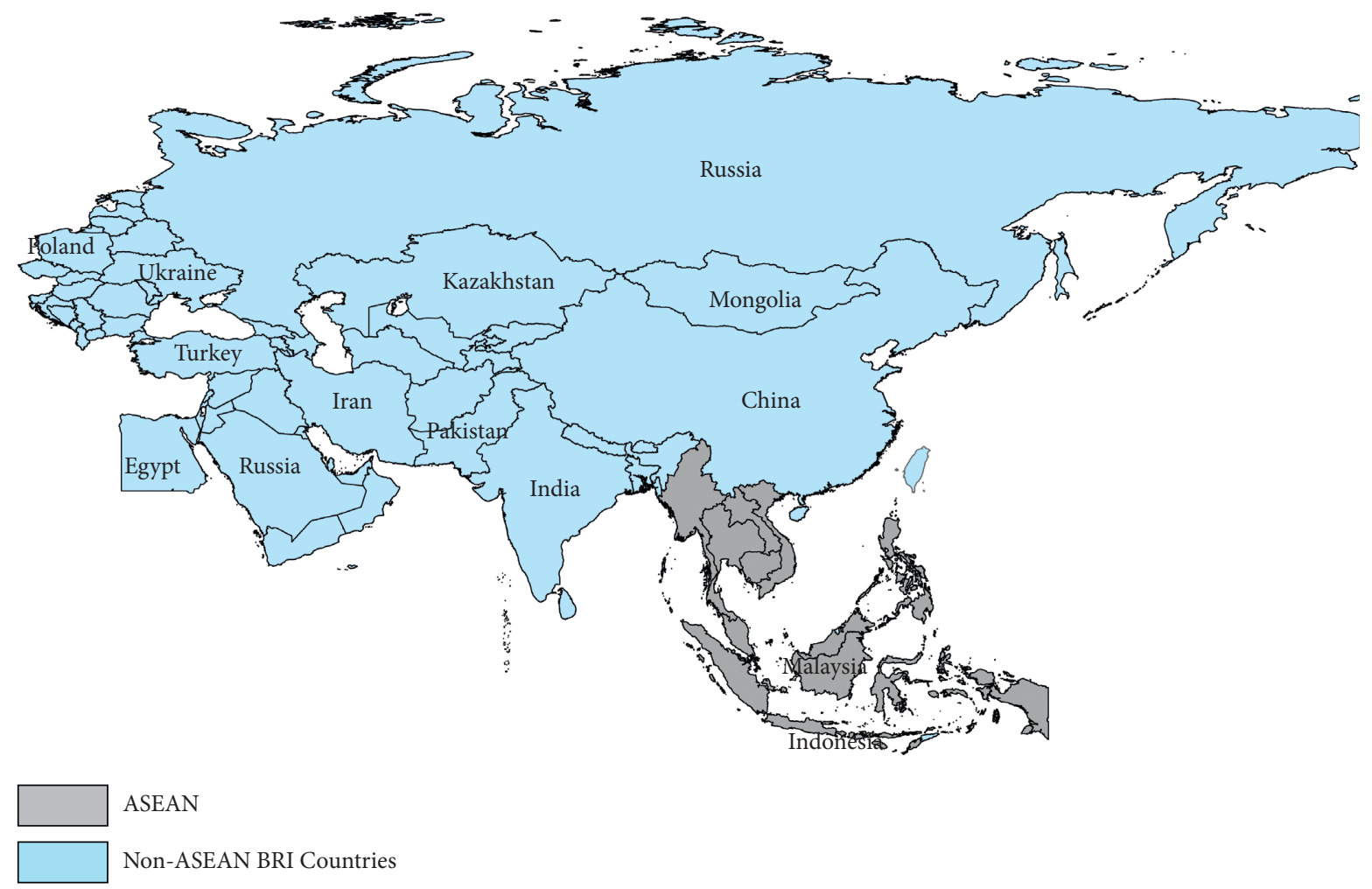

FIgURE 1: Map of the BRI countries in this paper.

input-output tables, there are a variety of databases compiled by many institutions, including the WIOD, GTAP, Eora26, Exiobase, and others. While most of the databases contain a small number of countries and regions, which is far from enough to cover the BRI countries, the Eora26 database compiled by the Lenzen team from the University of Sydney stands out as a relatively comprehensive one (https://worldmrio.com/eora26/). It covers 189 countries and regions around the world with a time span from 1990 to 2015. In addition, according to Qiao and others' [34] suggestion on data usage, we turn to adopt Eora26's intercountry input-output database. We extract the data of the 64 BRI countries in the years 2005, 2010, and 2015.

\subsection{Methods}

2.3.1. International Flow Accounting of VAT. International export trade products often contain inputs of imported raw materials from other countries. These raw material importing countries will also share export profits. To measure the true level of trade, it is necessary to calculate the actual value added in the exported products, i.e., the valueadded exports. The multiregional input-output model is commonly used to calculate the value-added exports between countries. In the multiregional input-output model, the Leontief model is as follows:

$$
X=(I-A)^{-1} f=B f .
$$


Assume that there are $m$ countries and each country is a single sector. By introducing the diagonal matrix of valueadded rate $\widehat{V}$, we can obtain

$$
V=\widehat{V} X=\widehat{V}(I-A)^{-1} f=\widehat{V} B f,
$$

where $\quad V=\left[\begin{array}{ccc}V^{11} & \ldots & V^{1 m} \\ \vdots & \ddots & \vdots \\ V^{m 1} & \ldots & V^{m m}\end{array}\right], \quad \widehat{V}=\left[\begin{array}{ccc}v^{1} & 0 & 0 \\ 0 & \ddots & 0 \\ 0 & 0 & v^{m}\end{array}\right]$, $A=\left[\begin{array}{ccc}A^{11} & \cdots & A^{1 m} \\ \vdots & \ddots & \vdots \\ A^{m 1} & \cdots & A^{m m}\end{array}\right], \quad B=(I-A)^{-1}=\left[\begin{array}{ccc}c^{11} & \cdots & c^{1 m} \\ \vdots & \ddots & \vdots \\ c^{m 1} & \cdots & c^{m m}\end{array}\right]$, $f=\left[\begin{array}{ccc}f^{11} & \cdots & f^{1 m} \\ \vdots & \ddots & \vdots \\ f^{m 1} & \cdots & f^{m m}\end{array}\right], X$ denotes the total output matrix driven by exports between countries, $I$ denotes the identity matrix with all diagonals being $1, A$ denotes the direct consumption coefficient matrix, $B$ denotes the Leontief inverse matrix, $f$ denotes the export trade volume between countries, $\widehat{V}$ denotes the diagonal matrix of the value-added rate of each country, and $V$ denotes the value-added export matrix between countries. By calculating the $V$ matrix, we can obtain the specific flow of VAT between two countries.

\subsubsection{Network Construction and Characteristic Analysis.} (1) Network Construction. This paper selects data of the three time sections of 2005, 2010, and 2015 to construct the trade network and VAT network. In the trade network, each country is regarded as a node and the export of one country to another country is used as the weight of the edge from that node to another node. Similarly, in the VAT network, the value-added export of a country to another country is used as the weight of the edge from that node to another node.

(2) Network Density. Based on the premise that the trade network and VAT network are weighted networks, we first normalize the trade flows. The normalized trade flow can be represented as $W_{i j}$, which ranges between 0 and 1 . The network density can be calculated as follows: $D=\left(\sum_{i=1}^{N} \sum_{j=1}^{N} W_{i j}\right) /(N(N-1)), i \neq j$, for $\sum_{i=1}^{N} \sum_{j=1}^{N} W_{i j}$ ranges from 0 to $N(N-1)$. Therefore, the density of weighted network will range between 0 and 1 .

(3) Community Detections. Since there are different trade communities in the BRI trade network, we also identify the trade communities in both of the trade network and the VAT network. Comparative analysis of the patterns and characteristics of the trade communities will help to understand the characteristics of both networks more thoroughly. Community detection is a common method to identify communities in the network $[16,35]$. In this paper, we employ the $Q$ function method proposed by Newman [36] to detect trade communities. When $Q$ reaches the maximum, we can obtain the best community division. The $Q$ function is introduced as follows:

$$
Q=\frac{1}{2 M} \sum_{i j}\left[\left(a_{i j}-\frac{k_{i} k_{j}}{2 M}\right) \delta\left(c_{i}, c_{j}\right)\right],
$$

where

$$
\delta\left(c_{i}, c_{j}\right)= \begin{cases}1, & \left(c_{i}=c_{j}\right), \\ 0, & \left(c_{i} \neq c_{j}\right) .\end{cases}
$$

In formulas (3) and (4), $c_{i}$ denotes the community to which node $i$ in the network belongs, $a_{i j}$ denotes the weight of node $i$ to node $j$, i.e., the trade flow from country $i$ to country $j, k_{i}$ denotes the sum of weights of the edge from node $i$, and $M$ denotes the sum of weights of all edges in the network.

(4) Eigenvector Centrality. Centrality measures the importance of the node in the network. For the trade network and VAT trade network, nearly all nodes are connected, but edges are weighted. Hence, the closeness centrality and betweenness centrality cannot well represent the importance of nodes. To solve this problem, in this paper, we use the eigenvector centrality index to measure the importance of nodes in the trade network and VAT network. The functional form of the eigenvector centrality is as follows:

$$
E C(i)=x_{i}=c \sum_{j=1}^{n} a_{i j} x_{j}
$$

where $x_{i}$ is the importance of node $v_{i}$, node $v_{j}$ is the neighbor of $v_{i}$, and $c$ is a proportional constant. Denoted by $x=\left[x_{1}, x_{2}, x_{3}, \cdots, x_{n}\right]^{T}$, when it reaches the steady state after several iterations, it can be written in the following matrix form:

$$
x=c A x
$$

This means that $x$ is the eigenvector corresponding to the eigenvalue $c^{-1}$ of matrix $A$. The basic method to calculate the vector $x$ is to give the initial value $x(0)$ and then use the following iterative algorithm:

$$
x(t)=c A x(t-1), \quad t=1,2, \ldots,
$$

until $x^{\prime}(t)=x^{\prime}(t-1)$. In the iterative process of each step, if $x$ is divided by the principal eigenvalue $\lambda$ corresponding to the adjacency matrix $A$, from this equation, we can obtain a nonzero solution, that is, $x=\lambda^{-1} A x$. Thus, the constant $c=\lambda^{-1}$.

\section{Results}

3.1. Comparative Analysis of Network Structure. We use the Gephi0.92 Software to visualize the constructed trade network and VAT network. Since there are too many edges in the network to make clear the visualization, we select the top $1 \%$ edges of the trade flows in each network to simplify the visualization. The visualized structures of both networks in the three time sections of 2005, 2010, and 2015 are shown in Figure 2. We can see that the density of both of the trade network and the VAT network increased at each stage from 2005 to 2015, and the weight of the edge became significantly larger. Combined with the network density calculation in Table 2, it fully shows the trade ties among the BRI countries have become closer. 

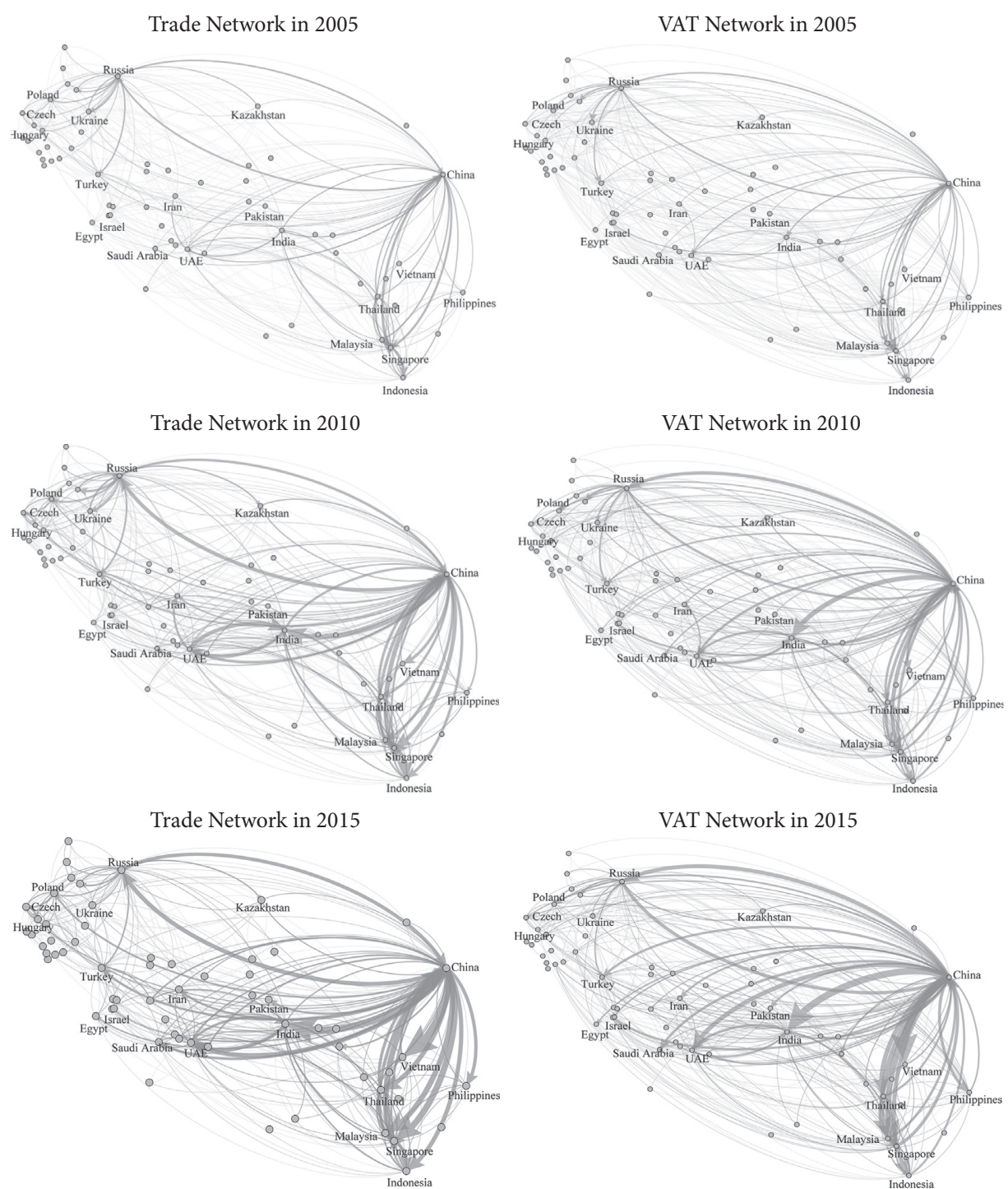

FIGURE 2: Network structure of the trade network and VAT network of the BRI countries.

TABLE 2: Network density of the trade network and the VAT network of the BRI countries.

\begin{tabular}{llll}
\hline Network density & 2005 & 2010 & 2015 \\
\hline Trade network & 0.184 & 0.385 & 0.474 \\
VAT network & 0.160 & 0.337 & 0.427 \\
\hline
\end{tabular}

From a subregional perspective, we can tell the trade density of Southeast Asian countries is much greater than that of the other regions at various time sections. This is because the ASEAN countries maintain relatively larger economy, and they have signed free trade agreements. Moreover, the manufacturing industry of the ASEAN countries is more advanced, establishing a more closely connected production network and a denser VAT network. In addition, the trade network and VAT network of South Asia with India as the core are developing rapidly. The internal trade links of Central and Eastern Europe with Russia as the core is also becoming closer. From 2005 to
2015, the trade and VAT between China and the countries along the BRI have increased significantly, especially between China and countries in Southeast Asia.

Comparing the trade network with the VAT network, we find that the density of the VAT network is lower than that of the trade network. This is mainly because the value-added rate of export products is usually less than 1 . The direction and volume of trade flows are also different. In the trade network, the two-way trade flows between China and the major BRI trading countries such as Southeast Asian countries, Russia, and India are obvious. In the VAT network, however, China's VAT outflow is more obvious. This 
shows that among the BRI countries, China is in a relatively high value-added position in the industrial chain, resulting in a greater VAT outflow than the inflow.

\subsection{Comparative Analysis of Network Centrality}

3.2.1. Evolution of Network Centrality. Network centrality is an important indicator to measure the status of nodes in the network. We calculate the centrality of the characteristic vector of both networks in 2005, 2010, and 2015 to show the status of trading countries in the BRI region. By selecting 10 major countries, we then analyze their ranking changes in the trade network and the VAT network. The result is shown in Figure 3.

Figure 3 shows that although China lagged behind Singapore in terms of trade network centrality and ranked second in 2005, it has always occupied the first position in the VAT network all through the years. Then, in 2010 and 2015, China's trade network centrality has also risen to the first place, which fully demonstrates China's core position in the BRI trade network and VAT network. Singapore, however, showed a downward trend of centrality in both trade network and VAT network from 2005 to 2015 and became the third in the rank of VAT network centrality. This is mainly due to the fact that most of Singapore's trade is reexport trade with relatively low value-added rate [37], which makes its participation index in the VAT network lower than that in the trade network.

From 2005 to 2015, countries with significant increases in the network centrality of both trade networks and VAT networks are India, Vietnam, and the United Arab Emirates (UAE). Among them, India's centrality in the VAT network rose from the sixth in 2005 to the third in 2010 and 2015. Vietnam shows the fastest rise in the rank, with its centrality rank in the VAT network growing rapidly from the twelfth in 2005 to the fourth in 2015. This shows that, in addition to rapid economic development, Vietnam also accelerates its integration into the regional production networks and regional value chains. The UAE, as an important country in West Asia, has a slight increase in position in the VAT network, from the eighth in 2005 to the sixth in 2015.

During the same period, the centrality of some countries in the networks has declined. Among them, Indonesia and Russia decreased the most. Indonesia's centrality in the trade network has dropped from the fourth to the eighth, and its centrality in the VAT network dropped from the sixth to the eighth. Because of the slow growth of domestic economic development, Russia's centrality in the value-added network slumped from the third in 2005 to the ninth place in 2015.

3.2.2. Distribution of Network Centrality. The distribution of network centrality reflects the polarization of the network cores, i.e., the variation in trading capacities of the BRI countries. Figure 4 indexes the evolution of centrality distribution of the trade network and the VAT network. It shows that the centrality distribution of either the trade network or VAT network in each specified year largely conforms to the power-law distribution; that is, the centrality of a few head countries are very large, and most other countries are at the edge of the network with low centrality. In detail, we can see that, in the trade network, from 2005 to 2010, although the relative central position of some countries has changed, the overall distribution of network centrality has not changed much. From 2010 to 2015, as China became the regional trading core country, the polarization has become distinctive with the large centrality gap between China and the other BRI countries, indicating China's expansion of its comparative advantage in the trade network. In the VAT network, the polarization of centrality distribution from 2005 to 2015 is more obvious. The centrality gap among the head countries began to expand as well. By comparing the trade network with the VAT network, we can tell a larger gap in centrality distribution of the VAT network than that of the trade network. China's central position in the VAT network is greater than that in the trade network.

Using Gephi 0.92, we further analyze the characteristics and evolution of the trade communities of trade network and VAT network of the BRI countries. The visualized result is shown in Figure 5.

In terms of the trade network, the division of trade communities mainly draws on geographical proximity to trade countries with strong centrality. In other words, the trade communities are shaped as certain large trade countries with neighboring small trade countries. Particularly, in the year of 2005, China and its surrounding Southeast Asian countries formed a main trade community. Russia led a trade community with the former Soviet Union countries. India formed a trade group with South Asia and some West Asian countries. Hungary, Turkey, and other Central and Eastern European countries constituted another trading community. Compared with 2005, the 2010 landscape of trade communities changed mainly because the trade community of China and Southeast Asia has divided into two separate communities, but the two trade communities of India and Middle East countries as well as South Asian countries have merged into one community. By the year 2015, China and ASEAN countries once again formed into one group, and the other trade communities have not changed much.

In terms of the VAT network, the community division also shows the characteristic of geographical proximity to large VAT countries. In 2005, most Southeast Asian countries formed a VAT community centering Singapore, while China formed another one with India and some West Asian countries. Russia still led a community with the former Soviet Union countries in the VAT network. In 2010, the VAT community of China and India has split up, with China turning to group with Southeast Asian countries and India forming a community with South Asian countries. Russia, together with some Central and Eastern European countries, formed a new VAT community. By 2015, the VAT community with China as the core has further expanded to include Russia, Mongolia, Central Asian countries, and Southeast Asian countries. India and South Asian countries remained as a separate VAT community.

Comparing the trade communities with the VAT communities, we find the overall patterns of the trade 

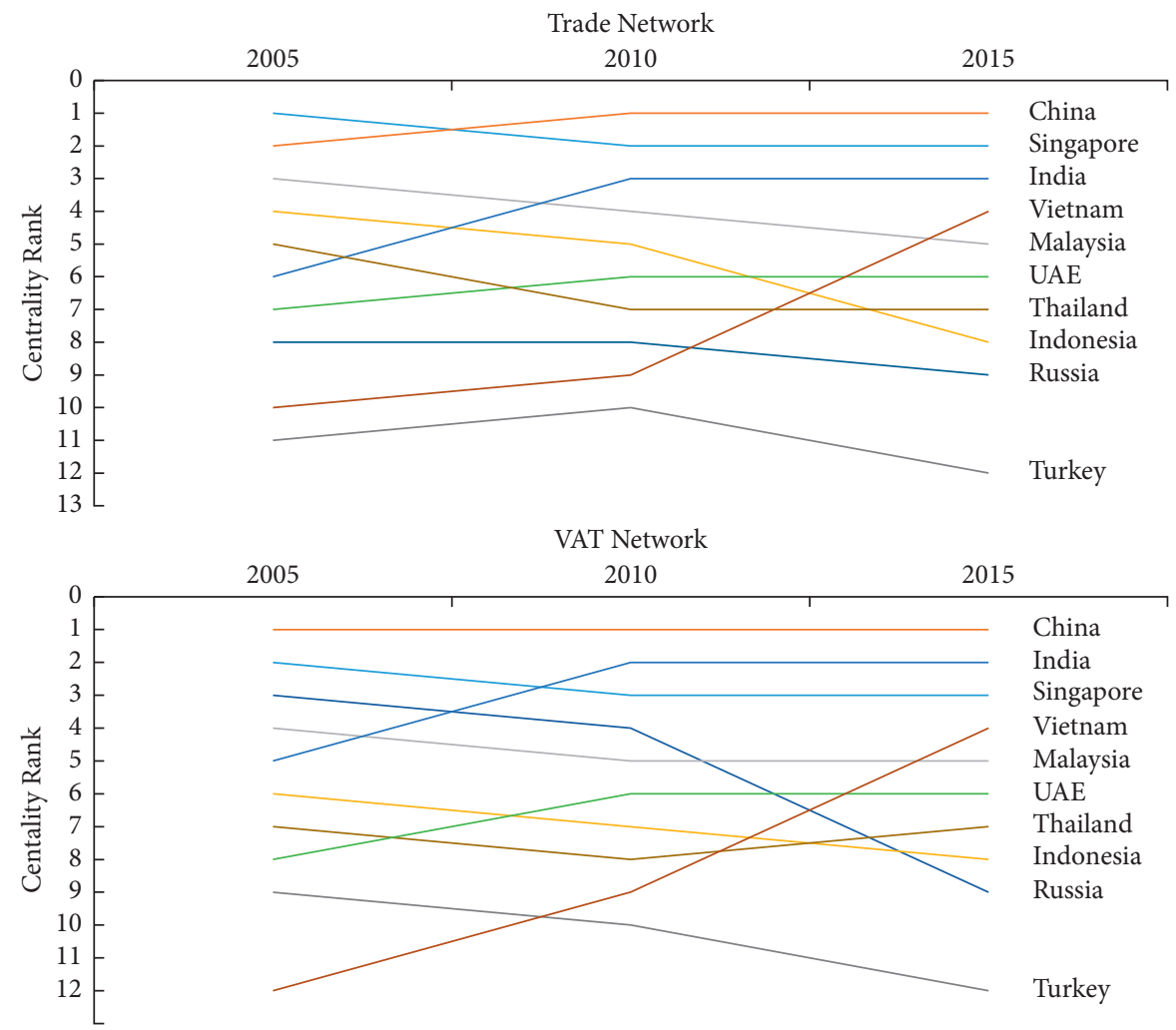

FIGURE 3: Evolution of network centrality of the trade network and the VAT network of major BRI countries.
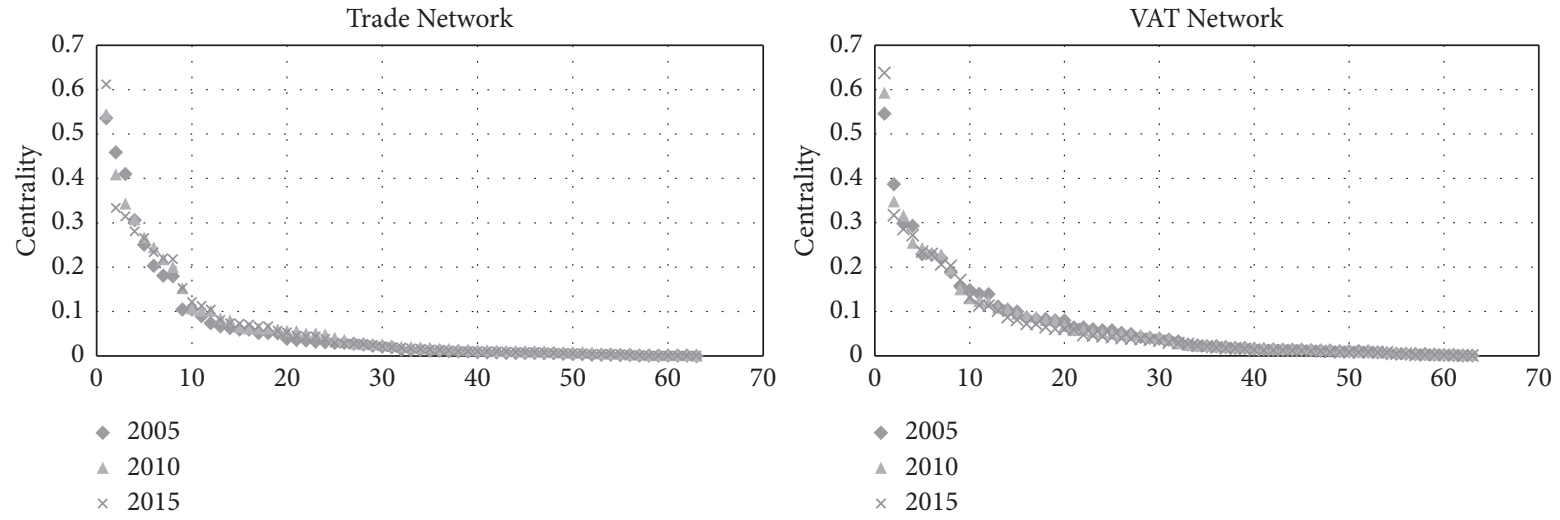

FIGURE 4: Distribution of network centrality of the trade network and the VAT network.

communities and the VAT communities represented differently all through the years. The overall pattern of the trade communities remains stable, while the overall patterns of the VAT communities changed a lot from 2005 to 2015. Specifically, in 2005, while China and Vietnam formed a trade community with other Southeast Asian countries, they were excluded from the VAT community of the Southeast Asian countries and were integrated into a separate one with countries in South Asia, West Asia, and Middle East. As West Asian and Middle East countries mainly relied on oil exports, we speculate China and Vietnam maintained quite amount of resource-based production. For Russia, it was involved in the same trade community with East European countries but formed a different VAT community without East European countries, indicating a weaker production cooperation than trade connection between Russia and the East Europe.

Then in 2010, China and Vietnam established stronger production connection with other Southeast Asian countries by forming an integrated VAT community but cut back trade connections with Singapore, Malaysia, Indonesia, and the others. Russia still maintained strong trade connection but weak production connection with the East Europe. Clearly, East European countries inclined to production cooperation with Central European countries. Such a VAT community composed by East European countries and Central European countries continued to the year 2015.

In 2015, the main difference between trade communities and VAT communities took place in Russia, the former Soviet Union countries, and Central Asian countries. These 

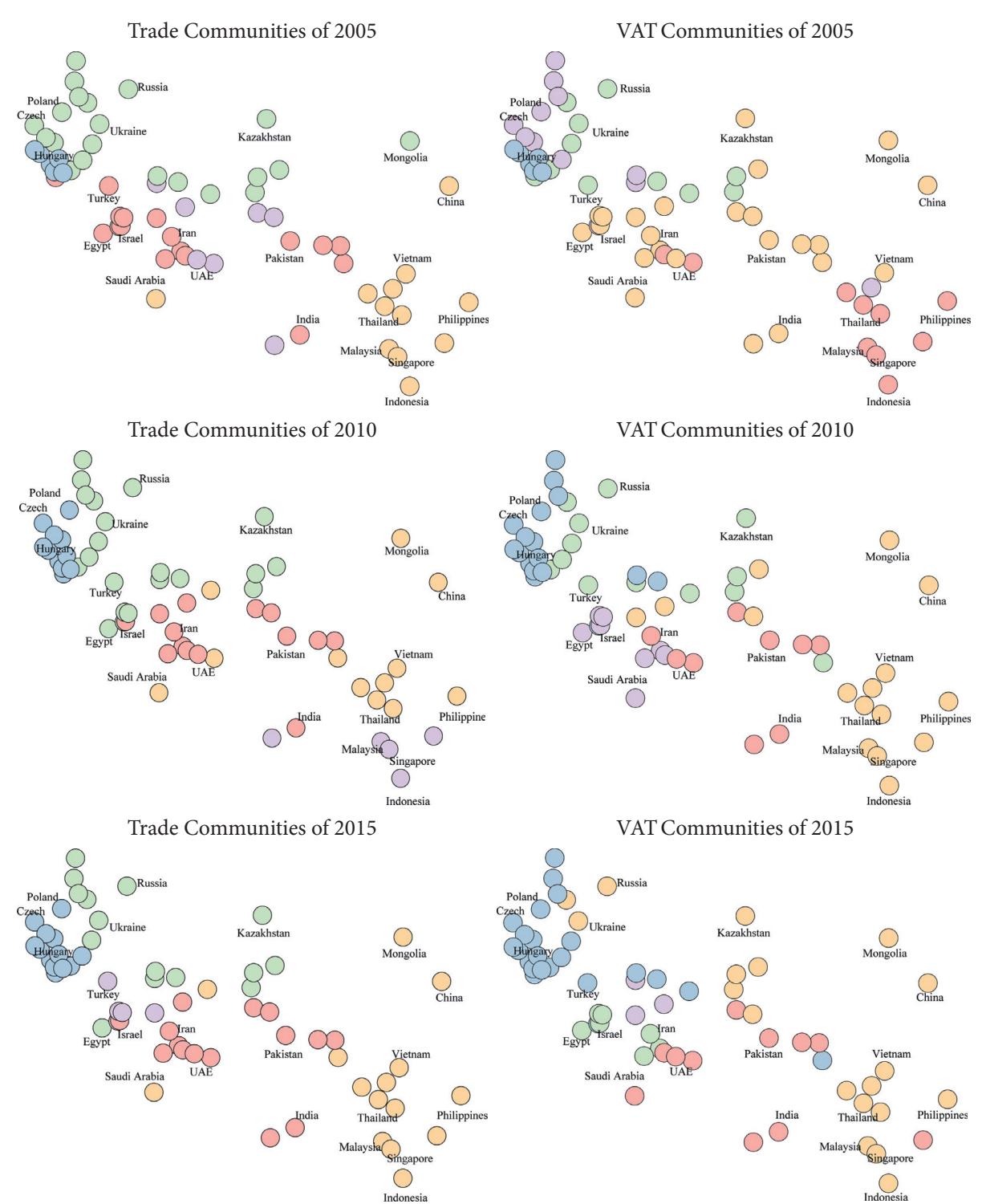

FIgURE 5: Comparison of trade communities and value-added trade communities of the BRI countries. Note. The spots indicate the geographical positions of national capitals. Spots in the same color belong to the same community.

countries formed an independent trade community but were separated into two different VAT communities: While Russia and Central Asian countries were involved in the same VAT community with China and Southeast Asian countries, the former Soviet Union countries joined the one with East and Central European countries. This result resonates with previous findings of Russia's decline in centrality and an increasingly obvious centrality polarization of the VAT network with China as the core all through the time period.

\section{Factors Influencing Network Development}

4.1. Econometric Model. Studies on international trade often include factors in aspects of economy, population, trade relations, and spatial distance to conduct empirical verifications of their impacts on trade network. Based on these studies, we try to investigate the factors that influence the development of BRI trade network and valued-added trade network from the following aspects. First, geographical distance, i.e., the spatial proximity between the trading countries, is an important factor, as we assume the closer the distance between countries, the easier the trade will happen. Economic distance also matters [38, 39]. In this paper, we take the difference in the GDP scale between the two countries as their economic distance. An excessive economic distance often indicates the two countries have large differences in resource endowments and production structure, which is not conducive to bilateral trade. Considering that only the economic distance cannot fully represent the impact of economy, we include the sum of the GDP of the two countries as a factor of the overall economic scale. Population size is another factor we take to reflect the market size of a country, which represents the demand for trade [39]. Moreover, we surmise countries that are bound to certain trade agreements will be more likely to trade with 
each other. As the BRI countries maintain different and independent trade agreements, such as The China-ASEAN Free Trade Area and the Russia-led EEU regional trade agreement [18], we also take the various trade agreements into the model. In addition, we understand common religion $[40,41]$ and language $[42,43]$ help reduce trade costs and facilitate trade. Taken together, we set up the model as follows:

$$
\ln (\mathrm{NW})=f\left[\ln \left(\mathrm{GDP}_{\text {diff }}\right), \ln \left(\mathrm{GDP}_{\text {sum }}\right), \ln \left(\mathrm{POP}_{\text {diff }}\right), \ln \left(\text { geo }_{\text {dist }}\right), \text { FTA, relig, lang } \text { off }_{f}\right]
$$

where NW indicates the network in Quadratic Assignment Procedure $(\mathrm{QAP})$ regression, $\mathrm{NW}_{\text {trade }}$ indicates the trade network, and $\mathrm{NW}_{\text {vat }}$ indicates the VAT network. They are the explained variables in the regression model.

For the explanatory variables, $\mathrm{GDP}_{\text {diff }}$ denotes the absolute value of the GDP difference and GDP sum $_{\text {menotes the }}$ sum of GDP. The unit of these two variables is current US dollar. $\mathrm{POP}_{\text {diff }}$ denotes the absolute value of the population difference. Its unit is person. geo $_{\text {dist }}$ denotes the matrix of geographic distance between the capital cities of the two countries. Its unit is kilometer. FTA denotes the matrix of a free trade agreement between the two countries (1 means there is a free trade agreement and 0 means there is not). relig denotes whether there is a common religion between the two countries. lang $_{\text {off }}$ denotes whether there is a common official language between the two countries.

4.2. Regression Results. Considering the high correlation of the network data, we draw on the QAP method for regression to avoid the influence from the multicollinearity of variables. The QAP regression method does not make strict requirements on the independence between variables. The purpose of QAP regression is to explore the regression relationship between multiple explanatory variable matrices and one explained variable matrix and to evaluate the regression results based on the regression coefficient and the regression fitted value $R^{2}$. Referring to the studies of Liu et al. [44] and Wang et al. [30], who have applied the QAP method in analyzing the BRI manufacturing network, we go further to investigate the factors that influence the trade network and the VAT network of the BRI countries. Due to the availability of data, we only perform the regression analysis for the 2015 data. The regression result is shown in Table 3.

For the trade network, the adjusted goodness of fit, i.e., the adjusted $R^{2}$, of the three models are $0.461,0.460$, and 0.455 , respectively. This means the variables included in the model can explain $46.1 \%, 46.0 \%$, and $45.5 \%$ of the corresponding network structure changes. The sample size of each model is 3906, indicating the model includes a $63 \times 63$ matrix composed of 63 countries (regions) along the BRI. The diagonal elements of the matrix are 0 ; that is, there is no self-loop in the network.

From the perspective of explanatory variables, the scale of GDP has obvious positive relationship with the trade links. Its coefficient is 4.092 in Model 1, significant at the significance level of $1 \%$. The regression coefficient of economic distance is -0.929 , significant at the significance level of $1 \%$, which shows that the economic distance has a significant hindering effect on trade links. The smaller the difference in economic size between countries, the more likely it is to generate stronger trade ties. The regression coefficient of population difference is -0.206 , significant at the significance level of $10 \%$, which also shows that the difference in population size has a relatively negative impact on trade links. The regression coefficients of geographic distance in the three models are -1.431 , -1.474 , and -1.318 , respectively, all significant at the $1 \%$ significance level. We can tell the greater the spatial distance between the two countries, the weaker the trade links become. The regression coefficient of the common religion is -1.634 , and it is significant at the $5 \%$ level of significance. Instead of promoting trade flows, the common religion exerts hindering effect on trade connections. The coefficients of FTA in the three models are 3.534, 3.565 , and 3.852, and they are all significant at the significance level of $1 \%$, which fully demonstrates that the signing of FTA between the two countries has a very positive effect on promoting trade ties between the two countries. Although the regression coefficient of the common official language is positive, it is not significant at the $10 \%$ significance level. It means the common official language has no significant impact on the trade links among the BRI countries.

The adjusted $R^{2}$ of the three regression models for the VAT network is $0.369,0.345$, and 0.332 , respectively, which means the variables could explain $36.9 \%$, $34.5 \%$, and $33.2 \%$ of the VAT network structural changes. From the perspective of regression coefficient, we could see the coefficient of the GDP scale is 2.167, with the significance level of $1 \%$. It shows that the larger the economic size of the two countries are, the closer the VAT ties between the two countries will be. However, the coefficient of economic distance is significantly negative, which adds the meaning that the GDP gap between the two countries should be small to promote the VAT. The coefficient of the population difference is also significantly negative, indicating a closer VAT link between countries with similar population sizes than those with large population difference. The regression coefficient of the common religion is still significantly negative. That is, having a common religion has a certain hindering effect on the VAT network. We speculate that the BRI countries that have common religions may maintain similar industrial structures or at the same level of economic development, which reduces the need of VAT. The free trade agreements still have a very significant positive impact on promoting 
TABLE 3: QAP regression result of the trade network and the VAT network in 2015.

\begin{tabular}{|c|c|c|c|c|c|c|}
\hline \multirow{2}{*}{ Variables } & \multicolumn{3}{|c|}{$\mathrm{NW}_{\text {trade }}$} & \multicolumn{3}{|c|}{$\mathrm{NW}_{\text {vat }}$} \\
\hline & Model (1) & Model (2) & Model (3) & Model (4) & Model (5) & Model (6) \\
\hline Intercept & $-55.33^{* * *}$ & $-53.28^{* * *}$ & $-54.69^{* * *}$ & $-24.55^{* * *}$ & $-21.08^{* *}$ & $-22.10^{* * *}$ \\
\hline $\ln \left(\mathrm{POP}_{\text {diff }}\right)$ & $-0.206^{*}$ & & & $-0.349^{* * *}$ & & \\
\hline $\ln \left(\mathrm{GDP}_{\text {sum }}\right)$ & $4.092^{* * *}$ & $3.914^{* * *}$ & $3.914^{* * *}$ & $2.167^{* * *}$ & $1.865^{* * *}$ & $1.839^{* * *}$ \\
\hline $\ln \left(\mathrm{GDP}_{\mathrm{diff}}\right)$ & $-0.929^{* * *}$ & $-0.949^{* * *}$ & $-0.955^{* * *}$ & $-0.481^{* * *}$ & $-0.515^{* * *}$ & $-0.506^{* * *}$ \\
\hline $\ln \left(\right.$ geo $\left._{\text {dist }}\right)$ & $-1.431^{* * *}$ & $-1.474^{* * *}$ & $-1.318^{* * *}$ & 0.062 & -0.011 & 0.139 \\
\hline relig & $-1.634^{* *}$ & $-1.660^{* *}$ & & $-1.182^{* *}$ & $-1.226^{* *}$ & \\
\hline FTA & $3.534^{* * *}$ & $3.565^{* * *}$ & $3.852^{* * *}$ & $0.803^{* * *}$ & $0.856^{* * *}$ & $0.980^{* * *}$ \\
\hline $\operatorname{lang}_{\text {off }}$ & 0.750 & 0.765 & & -0.321 & -0.294 & \\
\hline$R^{2}$ & 0.461 & 0.460 & 0.455 & 0.370 & 0.346 & 0.333 \\
\hline Adjusted $R^{2}$ & 0.461 & 0.459 & 0.455 & 0.369 & 0.345 & 0.332 \\
\hline Number of observations & 3906 & 3906 & 3906 & 3906 & 3906 & 3906 \\
\hline
\end{tabular}

Note. $^{* * *},{ }^{* *}$, and ${ }^{*}$, respectively, indicate significance at $1 \%, 5 \%$, and $10 \%$.

VAT links. Yet the influence of the geographic distance and the common official language are not significant in the VAT model.

Comparing the regression results of the trade network and the VAT network, we find factors of economic size, economic distance, population difference, common religion, FTA, and common language have similar impacts on both of the trade network and the VAT network. On the one hand, enlarging economic size of the trading countries and facilitating FTA will positively promote the trade ties and VAT ties. On the other hand, economic distance, population difference, and common religion have hindering effects on both networks. Geographical distance has different impacts on the trade network and VAT network. While the geographic distance significantly prevents the trade links between countries, its hindering effect on VAT links is not significant.

\section{Conclusions and Policy Suggestions}

5.1. Conclusions. In this paper, we first calculate the VAT flows among the BRI countries from 2005 to 2015 to construct the BRI trade network and VAT network. Applying the network analysis method, we further analyze and visualize the structures, characteristics and evolutions of both trade network and VAT network. Then, we investigate into the factors that influence the development of both networks using the QAP method. By comparing the network density, network centrality, trade communities, and the influencing factors of the two networks through the past decade, we draw the following conclusions:

(1) The density of both trade network and VAT network of the BRI countries has been risen. As the density of regional trade network increased rapidly, the BRI countries have been communicating with each other more frequently. Meanwhile, the density of VAT network has also grown largely, reflecting a more closely related regional production network. In a sense, we could tell a pattern of the BRI regional economic integration is taking shape.

(2) The center-external structure of the BRI region has been strengthened. The network centrality of the head countries in the BRI trade network is exponentially larger than that of the other countries. Such centrality gap has been widening continuingly through the years. This reflects a distinct centerexternal structure of the BRI trade network led by the regional core country of China and several subregional core countries, like Singapore, India, UAE, and Russia. Comparing with the trade network, the center-external structure of regional VAT network is more obvious. With an increasingly growing centrality gap with the other countries, China occupies an absolute core position in the value-added trade network and leads the regional production network.

(3) The patterns of the trade communities and the VAT communities were mainly based on geographical proximity to regional and subregional core countries. They looked largely different, indicating a diverse regional trade and production network. While the economic ties within trade communities have not changed too much from 2005 to 2015, the VAT communities have been gradually drawn together in the shape of several large agglomerations, i.e., the community of China with surrounding countries, the community of the Europe, the South Asian countries, and Middle East countries, and the community of other countries. It is noteworthy that, in 2015, the VAT community with China as the core grew to be larger than any other VAT communities and larger than the trade community with China as the core. It shows that China maintains greater influence in leading the regional VAT network.

(4) The influencing factors have similar impacts on the trade network and the VAT network. Growing economic scale and FTA signing have obvious positive effects on the strengthening trade links and VAT links; economic distance and population difference have a significant inhibitory effect. The main difference is the effect of geographical distance. While it has obvious hindering effect on the trade network, it does not necessarily influence the VAT network. 
5.2. Policy Implications. Unimpeded trade is one of the "five links" promoted by the BRI and the top priority of the BRI construction. Strengthening trade links among the BRI countries will facilitate regional economic development and promote the building of a community with a shared future for humankind. As the core country with the highest centrality in both the trade network and VAT network of the BRI region, China can play a more important role in promoting the trade ties among the BRI countries and leading regional socioeconomic development. Based on this research, we try to propose suggestions for a tighter, more deepening and more adequate regional economic cooperation pattern from the perspective of China:

First, China should further accelerate the transformation and upgrading of domestic industries and further enhance its position in the VAT network in the region. At the same time, China should promote the diffusion of industries to countries along the BRI and help promote their further integration into the global production network and global value chain to achieve common economic development.

Second, it is possible for China to advance the construction of broad trade channels within the BRI region. The broad trade channels will help reduce the trade cost between countries and promote intraregional trade links. They will also help regional industrial transfer and industrial connections and further enhance China's core position in the BRI trade network and VAT network.

Finally, China should help speed up the standardization of trade rules of the BRI region by promoting the signing of trade agreements among the BRI countries for reducing trade barriers. Meanwhile, with its central position in both the trade network and the VAT network, it is necessary for China to promote regional economic governance and facilitate intraregional trade links and production integration.

\section{Data Availability}

All data in this paper are available upon request.

\section{Conflicts of Interest}

The authors declare no conflicts of interest.

\section{Acknowledgments}

This research was funded by Foundation of Natural Science of Guangdong (No. 2019BT02H594), Major Project of National Social Science Foundation of China (No. 21ZDA097), and Guangdong Ordinary Universities Youth Innovative Talents Project (No. 2020WQNCX016).

\section{References}

[1] R. C. Johnson and G. Noguera, "Accounting for intermediates: production sharing and trade in value added," Journal of International Economics, vol. 86, no. 2, pp. 224-236, 2012.

[2] C. Prell, L. Sun, K. Feng, and W. T. Myroniuk, "Inequalities in global trade: a cross-country comparison of trade network position, economic wealth, pollution and mortality," PLoS One, vol. 10, Article ID e144453, 2015.
[3] D. Garlaschelli and M. I. Loffredo, "Structure and evolution of the world trade network," Physica A: Statistical Mechanics and Its Applications, vol. 355, no. 1, pp. 138-144, 2005.

[4] L. De Benedictis and L. Tajoli, "The world trade network," The World Economy, vol. 34, no. 8, pp. 1417-1454, 2011.

[5] G. Fagiolo, J. Reyes, and S. Schiavo, "On the topological properties of the world trade web: a weighted network analysis," Physica A: Statistical Mechanics and Its Applications, vol. 387, no. 15, pp. 3868-3873, 2008.

[6] I. Tzekina, K. Danthi, and D. N. Rockmore, "Evolution of community structure in the world trade web," The European Physical Journal B, vol. 63, no. 4, pp. 541-545, 2008.

[7] G. Fagiolo, J. Reyes, and S. Schiavo, "The evolution of the world trade web: a weighted-network analysis," Journal of Evolutionary Economics, vol. 20, no. 4, pp. 479-514, 2010.

[8] X. Jiang, Y. Yang, and S. Wang, "Spatial and temporal patterns of evolution of global trade networks during 1985-2015 and its enlightenment to China's geostrategy," Geographical Research, vol. 37, pp. 495-511, 2018.

[9] Y. Yang, J. P. H. Poon, Y. Liu, and S. Bagchi-Sen, "Small and flat worlds: a complex network analysis of international trade in crude oil," Energy, vol. 93, pp. 534-543, 2015.

[10] X. Hao, H. An, X. Sun, and W. Zhong, "The import competition relationship and intensity in the international iron ore trade: from network perspective," Resources Policy, vol. 57, pp. 45-54, 2018.

[11] S. Torreggiani, G. Mangioni, M. J. Puma, and G. Fagiolo, "Identifying the community structure of the food-trade international multi-network," Environmental Research Letters, vol. 13, p. 54026, 2018.

[12] N. E. K. Petridis and E. Stiakakis, "Global e-waste trade network analysis," Resources, Conservation and Recycling, vol. 158, Article ID 104742, 2020.

[13] G. Dong, T. Qing, L. Tian, R. Du, and J. Li, "Optimization of crude oil trade structure: a complex network analysis," Complexity, vol. 2021, Article ID 3480546, 11 pages, 2021.

[14] M. H. Schütz and N. Palan, "Restructuring of the international clothing and textile trade network: the role of Italy and Portugal," Journal of Economic Structure, vol. 5, pp. 1-29, 2016.

[15] T. Kito and K. Ueda, "The implications of automobile parts supply network structures: a complex network approach," CIRP Annals, vol. 63, no. 1, pp. 393-396, 2014.

[16] Z. Liu, T. Wang, J. W. Sonn, and W. Chen, "The structure and evolution of trade relations between countries along the Belt and Road," Journal of Geographical Sciences, vol. 28, no. 9, pp. 1233-1248, 2018.

[17] J. Zou and W. Liu, "Trade network of China and countries along "Belt and Road Initiative"areas from 2001 to 2013," Scientica Geographica Sinica, vol. 36, pp. 1629-1636, 2016.

[18] Z. Chong, C. Qin, and S. Pan, "The evolution of the Belt and Road trade network and its determinant factors," Emerging Markets Finance and Trade, vol. 55, no. 14, pp. 3166-3177, 2019.

[19] Q. Chen, J. Cheng, and Z. Wu, "Evolution of the cultural trade network in "the belt and Road" region: implication for global cultural sustainability," Sustainability, vol. 11, no. 10, p. 2744, 2019.

[20] Z. Song, S. Che, and Y. Yang, "The trade network of the Belt and Road Initiative and its topological relationship to the global trade network," Journal of Geographical Sciences, vol. 28, no. 9, pp. 1249-1262, 2018.

[21] Z. Song, S. Che, and Y. Yang, "Topological relationship between trade network in the Belt and Road Initiative area and 
global trade network," Progress in Geography, vol. 36, pp. 1340-1348, 2017.

[22] H. Xu, T. Sun, and L. Cheng, "Trade patterns and influence factors of high-end manufacturing on "One Belt and One Road" - a study based on the exponential random graph models," Finance \& Trade Economics, vol. 36, pp. 74-88, 2015.

[23] M. Zhan, "Research on the competitiveness and complementarities of agricultural product trade of countries along "the belt and Road": based on social network analysis method," Issues in Agricultural Economy, vol. 2, pp. 103-114, 2018.

[24] C. Zhang, J. Fu, and Z. Pu, "A study of the petroleum trade network of countries along "The Belt and Road Initiative"," Journal of Cleaner Production vol. 222, pp. 593-605, 2019.

[25] B. Ferrarini, "Vertical trade maps," Asian Economic Journal, vol. 27, no. 2, pp. 105-123, 2013.

[26] F. Cerina, Z Zhu, A. Chessa, and M. Riccaboni, "World inputoutput network," PLoS One, vol. 10, Article ID e0134025, 2015.

[27] Z. Zhu, M. Puliga, F. Cerina, A. Chessa, and M. Riccaboni, "Global value trees," PLoS One, vol. 10, Article ID e0126699, 2015.

[28] J. Amador and S. Cabral, "Networks of value-added trade," The World Economy, vol. 40, no. 7, pp. 1291-1313, 2017.

[29] T. Sun, H. Xiao, B. Meng, and H. Xu, "Topology and evolutionary pattern of manufacturing gvc network and its influencing factors: a study based on wwz method and social networks," Management Revue, vol. 30, pp. 49-60, 2018.

[30] B. Wang, N. Chen, and G. Lin, "Network structure of valueadded trade in manufacturing of "Belt and Rood" countries and its influencing factors," Journal of International Trade, vol. 3, pp. 85-100, 2019.

[31] F. de Soyres, F. de Soyres, and A. Gaillard, "Value added and productivity linkages across countries," FRB International Finance Discussion Paper, No. 1266, Board of Governors of the Federal Reserve System, Washington, DC, USA, 2019.

[32] W. Liu, "Scientific understanding of the Belt and Road Initiative of China and related research themes," Progress in Geography, vol. 34, pp. 538-544, 2015.

[33] J. Zou, C. Liu, G. Yin, and Z. Tang, "Spatial patterns and economic effects of China's trade with countries along the Belt and Road," Progress in Geography, vol. 34, pp. 598-605, 2015.

[34] X. Qiao, Z. Li, and N. Xiang, "Tracing the embodied carbon in intermediate goods trade and a parallel comparison among multi-regional databases," Finance \& Trade Economics, vol. 39, pp. 84-100, 2018.

[35] M. T. Schaub, J.-C. Delvenne, M. Rosvall, and R. Lambiotte, "The many facets of community detection in complex networks," Applied Network Science, vol. 2, no. 1, p. 4, 2017.

[36] M. E. J. Newman and M. Girvan, "Finding and evaluating community structure in networks," Physical Review E, vol. 69, no. 2, p. 26113, 2004.

[37] K. M. Choy, "Trade cycles in a re-export economy: the case of Singapore," International Economic Journal, vol. 26, no. 2, pp. 189-201, 2012.

[38] F. Kimura and H.-H. Lee, "The gravity equation in international trade in services," Review of World Economics, vol. 142, no. 1, pp. 92-121, 2006.

[39] X. Yao, B. Wang, and Y. Pu, "The network structure characteristics and influence factors of the service intermediate input about the countries along "the Belt and Road", World Economy Study vol. 1, pp. 122-133+136, 2018.
[40] H. L. F. De Groot, G.-J. Linders, P. Rietveld, and U. Subramanian, "The institutional determinants of bilateral trade patterns," Kyklos, vol. 57, no. 1, pp. 103-123, 2004.

[41] J. J. Lewer and H. Van den Berg, "Religion and international trade: does the sharing of a religious culture facilitate the formation of trade networks?" The American Journal of Economics and Sociology, vol. 66, no. 4, pp. 765-794, 2007.

[42] J. Melitz, "Language and foreign trade," European Economic Review, vol. 52, no. 4, pp. 667-699, 2008.

[43] J. Lohmann, "Do language barriers affect trade?" Economics Letters, vol. 110, no. 2, pp. 159-162, 2011.

[44] H. Liu, Y. Zhang, and Y. Sun, "The spatial network structure of China's regional development and its determinants," Economic Review, vol. 5, pp. 59-69, 2015. 